\title{
MeCo: A Digital Card Game to Enhance Metacognitive Awareness
}

\author{
Eelco Braad ${ }^{1,2}$, Nick Degens ${ }^{1} \&$ Wijnand IJsselsteijn ${ }^{2}$ \\ ${ }^{1}$ Research Group User-Centered Design, Hanze University of Applied Sciences Groningen, The Netherlands \\ ${ }^{2}$ Human-Technology Interaction Group, Eindhoven University of Technology, The Netherlands \\ e.p.braad@pl.hanze.nl \\ d.m.degens@pl.hanze.nl \\ w.a.ijsselsteijn@tue.nl
}

\begin{abstract}
A key concept within 21st-century skills is knowing how to acquire new knowledge and skills. Metacognition is the knowledge a person has of their own learning combined with the skills to apply that knowledge to enable more efficient and effective learning. Game-based learning can stimulate motivation as well as learning, but while various reviews have pointed out the opportunity for digital games to promote metacognition, little is known about how games can be designed to accomplish this. If we want learners to become better at learning with games, we need to investigate how metacognition can be supported and trained through game-based learning.
\end{abstract}

Previous research has identified generic principles for designing metacognitive training, while only a few principles specific to game-based learning have been suggested. We designed the mobile game MeCo based on these design principles. MeCo was inspired by the mobile game Reigns and replicates its mechanic of exploring a dynamically branching story through choice-making by swiping cards left or right. However, in MeCo the objective is to learn as much as possible about different planets and their inhabitants, by planning, performing, and evaluating space exploration missions. Two metacognitive interventions were added to promote the transfer of metacognition to real-world learning situations: metacognitive question prompts and metacognitive feedback.

A preliminary evaluation of the game was conducted using questionnaires and focus groups. Players found the game motivating enough to engage with the story and to be willing to play the game in their free time. Furthermore, they found that their in-game choices mattered, although more linear parts were preferred over more dynamically branching parts of the game. However, the humour in the narrative interfered with the more serious nature of metacognitive questions, resulting in players not taking the questions seriously enough to have an impact on metacognitive awareness. The implications for designing motivating digital games to enhance metacognition are discussed.

Keywords: game-based learning, games for learning, metacognition, design-based research

\section{Introduction}

A key concept within 21st century skills is being able to acquire new knowledge and new skills to foster lifelong learning, self-direction, and problem-solving (Koenig, 2011). The knowledge a person has about their own learning, and the ability to apply that knowledge to enable more efficient and effective learning, are commonly referred to as metacognitive awareness (Brown, 1978; Flavell, 1976; Schraw, 1998). Metacognitive knowledge comprises knowledge of oneself as a learner (person knowledge), knowledge of how to perform cognitive tasks (task knowledge), and knowledge of when and why to use person and task knowledge (strategy knowledge) for learning. Metacognitive skills comprise planning, monitoring, regulating, and evaluating learning activities (Jacobs \& Paris, 1987; Schraw, 1998; Veenman, Van Hout-Wolters, \& Afflerbach, 2006), aligning closely with the self-regulated learning cycle of forethought, performance, and self-reflection (Zimmerman \& Campillo, 2003). As metacognition intersects with self-regulation, self-direction, problemsolving, and in general knowing how to learn effectively, it is a critical component in fostering $21^{\text {st }}$-century skills.

Game-Based Learning (GBL) is an interactive form of learning that combines motivational aspects of games, such as challenge and fantasy, with learning aspects, such as practising in a risk-free environment with scaffolding and feedback (Plass, Homer, \& Kinzer, 2015). Various reviews have demonstrated that GBL may indeed foster motivation as well as learning, and have proposed that GBL may additionally be leveraged to enhance learners' metacognitive knowledge and skills (Ke, 2016; Sitzmann, 2011). However, only a few 
successful examples of training metacognition through GBL have been published (e.g. Castronovo, Van Meter, \& Messner, 2018; Kim, Park, \& Baek, 2009) and, more importantly, little is known about why these GBL-designs were successful. In other words, it is currently unknown which generic design principles can be followed to successfully foster metacognition in GBL. If we want learners to become better at learning with games, we need to investigate how metacognition can be enhanced through game-based learning.

In the remainder of this paper we present the design and preliminary evaluation of $\mathrm{MeCo}$, a game to enhance metacognitive awareness, as a case study of how design principles for fostering metacognition in GBL can be linked to a concrete design artefact. First, we discuss generic and GBL-specific design principles for designing games that foster metacognition. Second, we discuss the design of MeCo and how the design principles were implemented. Last, we discuss a preliminary evaluation of MeCo and the implications for design and further research.

\section{Design Principles for Metacognitive Training}

Research into metacognitive training has led to several generic design principles, while design principles specific to GBL are lacking. Four generic design principles for designing metacognitive training that are widely supported among researchers are:

a) inform learners of the goals and benefits of metacognitive training and emphasises its usefulness, to make sure students are motivated to invest the (initial) additional effort (Bannert \& Mengelkamp, 2013; Lin, 2001; Veenman et al., 2006);

b) provide learners with enough time, prolonged training, and frequent assessment opportunities to allow them to implement and automate metacognition (Bannert \& Mengelkamp, 2013; Lin, 2001; Veenman et al., 2006);

c) if possible, provide learners with concrete standards against which to evaluate comprehension (Osman \& Hannafin, 1992);

d) help learners to express their own ways of thinking, in particular by discussing with other learners (Lin, 2001; Osman \& Hannafin, 1992).

In addition to these generic design principles for metacognitive training, literature research revealed only two publications that attempt to formulate specific design principles for fostering metacognition within GBL: Mayer (2016) has formulated six design principles to foster metacognition within games in the domain of science, technology, engineering, and mathematics (STEM), and Nietfeld \& Shores (2011) have provided a number of future directions for promoting self-regulated learning (SRL), including metacognition, within GBL. The GBLspecific design principles from both works can be summarised as follows:

e) stimulate learners to self-explain their problem-solving processes and provide learners with support aids and guided practice - such as through feedback, scaffolding, and modelling;

f) keep a balance between "fun" and "seriousness" - for example by adding personalisation and avoiding too much unnecessary realism;

g) use collaboration between peer learners and/or supervisors and use the affordances of GBL for adding collaboration with virtual companions;

h) support the three SRL-phases of planning, performance, and evaluation throughout the training.

While some researchers emphasise that metacognitive training must be embedded in the domain-specific content matter to foster connectivity (e.g. see Bannert \& Mengelkamp, 2013; Veenman et al., 2006), others emphasise the domain-general nature of metacognition (e.g. see Schraw, 1998; but also see Veenman et al., 2006). Such domain-general training must ensure that learners can make the connection to domain-specific content and can identify transferrable metacognitive knowledge and skills (Derry \& Murphy, 1986; Osman \& Hannafin, 1992). The benefit of domain-general training is that it can be employed across a wider range of domains and thus combines frequent training opportunities with general applicable learning skills.

\section{Design}

Based on the generic and GBL-specific design principles, we designed MeCo: a domain-generic game to enhance metacognitive awareness. MeCo was inspired by the mobile game Reigns (Nerial, 2016) and replicates 
its mechanic of exploring a dynamically branching story through choice-making by swiping cards left or right. However, instead of attempting to manage a medieval kingdom, in $\mathrm{MeCo}$, the objective is to learn as much as possible about different planets and their inhabitants by planning, performing, and evaluating space exploration missions.

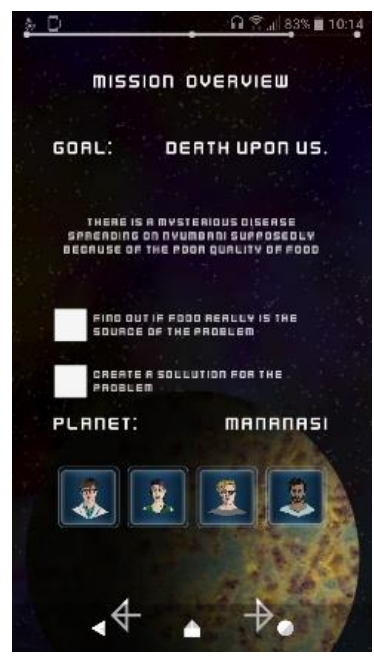

(a)

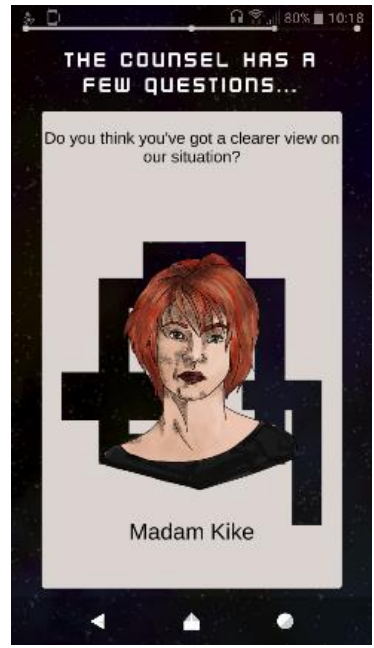

(d)

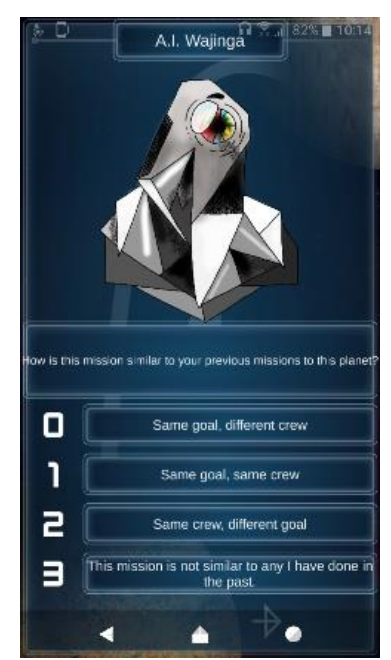

(b)

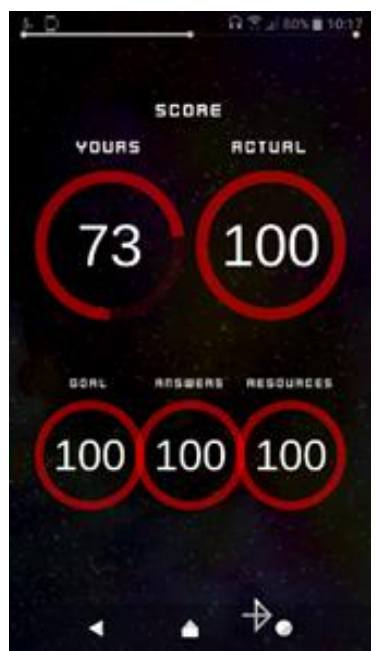

(e)

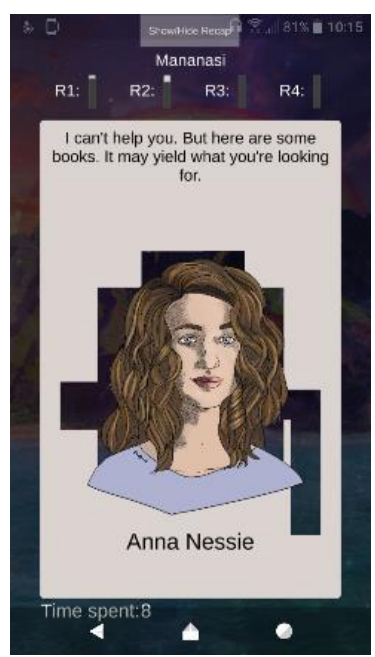

(c)

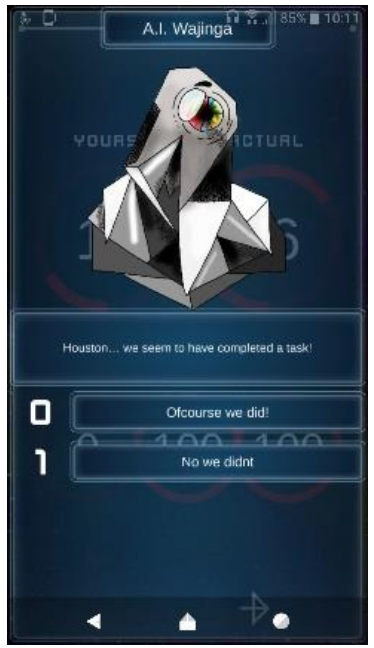

(f)

Figure 1 (a)-(f): An overview of different screens in MeCo: (a) mission overview, (b) metacognitive question during planning, (c) crew member suggestion during performance, (d) senior council member during revaluation, (e) comparison of estimated and actual mission success, and (f) metacognitive question during performance.

\subsection{Theme and Goal}

The setting of the game was established after a majority of students in higher education, when asked about their game theme preferences, indicated that they would be interested in a game about space exploration. This also allowed us to embed learning in the narrative of the game: the player is tasked to organise space missions to learn as much as possible about life on other planets. In this way, the game introduces a metaphor of learning as an aid to relate in-game choices to real world learning (cf. Charles et al., 2012).

\subsection{Narrative and Gameplay}

The game implements a system that dynamically branches the narrative through the binary choices the player makes. This allows players to explore a wide range of possible outcomes, while each choice is simple in itself. As the core gameplay loop, the game adopts the self-regulated learning cycle of planning, performance, and 
evaluation in the form of a space exploration mission and thus emphasises the metacognitive skills of planning, monitoring, regulating, and evaluating learning activities.

\subsection{Planning, Performance, and Evaluation}

In the planning phase, players are briefed about the problems on their own planets and what needs to be learned, through an interactive conversation with a senior council member character. Subsequently, players are free to choose a learning goal (e.g. learn about a cure for a peculiar disease), select a planet to learn from (e.g. that experiences similar symptoms), and assemble a crew of four to participate in the mission (e.g. crew with medical knowledge and skills). In this way, players have control over which learning goal to pursue and in what way to pursue that learning goal (see Figure 1a), thus simulating the planning phase of self-regulated learning.

In the performance phase, players embark on the mission and interact with the crew members to monitor and regulate the activities employed to learn about the planet and its inhabitants. Monitoring is simulated by crew members presenting themselves to the player with findings and issues occurring as part of the mission, which requires players to assess learning progress. Players can then regulate the learning activities in the mission by swiping the crew member card to the left or to the right to make a choice. In some cases, crew members will ask for a decision on what the best way is to learn. In this way, the crew members are virtual characters that simulate discussing learning, learning progression and learning activities as learners would among each other in the real world. For example, at one point a character suggests consulting books as a means of learning, which the player can choose to approve or disregard (see Figure 1c): this is analogous to a learner deciding if consulting a book is an appropriate learning strategy given the learning objectives. As such, the game simulates the performance phase of self-regulated learning.

In the evaluation phase, players see a mission recap after which they are asked to make their own estimation of success explicit by indicating a percentage of successfulness on an interactive wheel. In other words: players are asked to evaluate how much was learned during the mission. Immediately afterwards, they receive their actual mission success rating and feedback on whether their self-evaluation was accurate (see Figure 1e). In this way, players receive direct feedback (on mission success) as well as metacognitive feedback (on the accuracy of estimating mission success) in a quantitative way (cf. Verpoorten et al., 2012). Finally, the mission is debriefed through a series of reflective questions posed by the senior council member that also provided the briefing. For example, the senior may ask the player if the mission provided more clarity with regard to the learning goals set during the planning stage (see Figure 1d). Through this conversation, players explicate their own view of how the mission was performed and why the mission was successful in a qualitative way. In this way, the game simulates the evaluation phase of self-regulated learning.

\subsection{Metacognitive Questions}

The features discussed so far are aimed at encouraging metacognitive processes within players within the game environment. To encourage transfer of metacognitive processes while playing to applying them in realworld learning, we have generated 20 different metacognitive questions that can be posed during the three different phases of the game. These questions are presented to the player by a separate character that is introduced as a robot assistant to the player and players can respond to the questions by selecting one of the multiple-choice options (see Figure 1b). For example, the assistant robot may suggest that a task has been completed, but the assessment of whether that is correct is left to the player (see Figure 1f), thus simulating a metacognitive judgment-of-learning. Another example is when the assistant robot asks the player what could be done differently next time to perform better - thus simulating a learner reflecting on learning activities and outcomes.

\subsection{Design of Features and Design Principles}

The design of the game MeCo is based on generic and GBL-specific design principles with respect to enhancing metacognitive awareness. As such, the game implements these principles in a concrete artefact that can be evaluated. In addition to evaluating this particular artefact, our aim is to evaluate its underlying design principles with the objective of informing future designers and researchers on how to enhance metacognitive awareness in different designs and artefacts. The links between each major feature and the design principles is summarised in Table 1. 
Table 1: An overview of how MeCo's game features implement the metacognitive design principles.

\begin{tabular}{|l|c|c|c|c|c|c|c|c|}
\hline & \multicolumn{5}{|c|}{ Design Principles } \\
\hline Game Feature in MeCo & $\underline{\text { a }}$ & $\underline{\mathbf{b}}$ & $\underline{\mathbf{c}}$ & $\underline{\mathbf{d}}$ & $\underline{\mathbf{e}}$ & $\underline{\mathbf{f}}$ & $\mathbf{g}$ & $\underline{\mathbf{h}}$ \\
\hline metaphor for learning is embedded in goals and narrative & $\mathrm{x}$ & & & & & $\mathrm{x}$ & & \\
\hline dynamically branching narrative allows many different playthroughs & & $\mathrm{x}$ & & & & & & \\
\hline binary choice-making allows frequent assessment and adjustment & & $\mathrm{x}$ & $\mathrm{x}$ & & & & & \\
\hline planning, performing, and evaluating adopted as the core gameplay loop & $\mathrm{x}$ & $\mathrm{x}$ & & & & $\mathrm{x}$ & & $\mathrm{x}$ \\
\hline players control which learning goal to pursue and in what way & & & & $\mathrm{x}$ & $\mathrm{x}$ & & & \\
\hline virtual characters simulate discussing learning with peers & & & $\mathrm{x}$ & & $\mathrm{x}$ & $\mathrm{x}$ & \\
\hline direct feedback on mission success & & $\mathrm{x}$ & $\mathrm{x}$ & & $\mathrm{x}$ & & & \\
\hline metacognitive feedback on accuracy of estimating mission success & & $\mathrm{x}$ & $\mathrm{x}$ & & $\mathrm{x}$ & & & \\
\hline players explicate how a learning mission was performed & & & & $\mathrm{x}$ & $\mathrm{x}$ & & & \\
\hline players explicate why a learning mission was successful & & & $\mathrm{x}$ & $\mathrm{x}$ & & & \\
\hline metacognitive questions connect in-game fantasy to real-world learning & $\mathrm{x}$ & & $\mathrm{x}$ & $\mathrm{x}$ & & $\mathrm{x}$ & \\
\hline
\end{tabular}

\section{Evaluation}

A preliminary evaluation of the game was conducted, in which 7 students in higher education (5 male, 2 female, aged 22-26 years) played MeCo for approximately 20 minutes. In this time, all participants played two missions. During play, basic analytics of interacting with the game were collected. After playing, all participants completed a questionnaire and participated in a focus group session. Both the questionnaire and the focus group were aimed at assessing the usability and user experience of the game, as well as narrative engagement, motivation, and metacognitive reflection of the players.

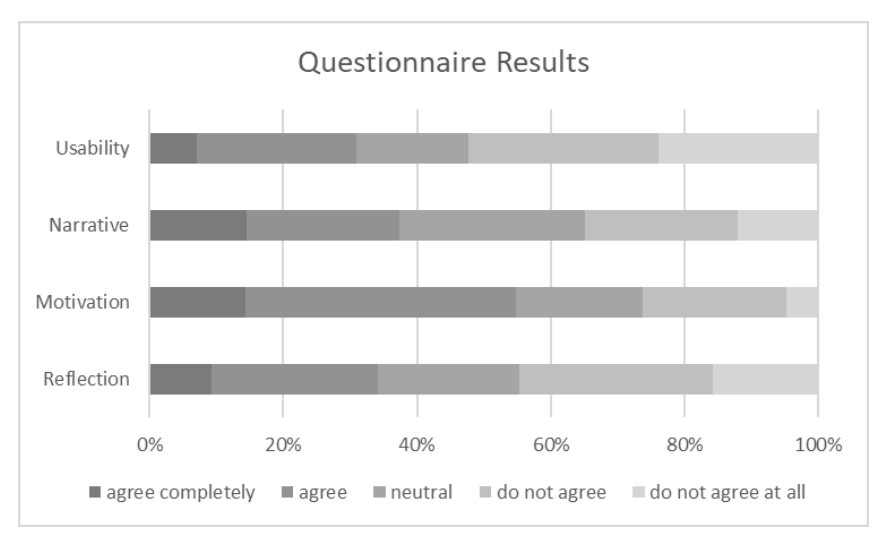

Figure 2: Overview of the questionnaire results.

The questionnaire results are summarised in Figure 2. The results from both the questionnaire and the focus groups are discussed below.

\subsection{Usability and User Experience}

The results from the questionnaire indicate that players struggled with the usability of the game. The focus groups revealed that, for some players, it was initially unclear how they could enact their choices by swiping a card left or right. However, although unclear at first, in the end the swiping of cards was considered a satisfying interaction by all participants.

\subsection{Narrative}

The story, characters, and choice-making were all rated positively in the questionnaire. Players reported in the focus groups that they felt that their choices in the game mattered while on a mission (performance phase). However, after completing a mission, players were disappointed with the lack of consequences for not performing well (evaluation phase). 
The dynamically branching narrative system sometimes selected follow-up cards that caused confusion. Players perceived a diminished sense of control as the game's response did not make sense to them with respect to their previous choice. In contrast, a more linear branch of the game's narrative was perceived as immersive and clear. Overall, the complicated branching of the story sometimes caused disengagement of players.

\subsection{Motivation}

The results from the questionnaire indicate that overall players were motivated to play the game. Analytics collected during play show that players spent an average of 7 seconds reading each card before selecting a choice. If we assume that this time is spent reading and interpreting the short text on the card, this response time could be an indication for interest in the story and active involvement in play - however, without further measurements we cannot verify this. Furthermore, players indicated that they would like to play again, in particular to explore different outcomes when making different choices. As a self-reported intention to play again is different from actual replay, further research is needed to see if players would indeed play the game again and read the cards when given a free choice.

Additionally, players elaborated during the focus groups that they would only play this game in their free time if there was a better build-up of characters and if failing a mission would have in-game consequences. Some players suggested that the game would be more interesting for them to play if the link to metacognition and improved learning in the real-world was made more clearly. In general, the theme, story, mechanics, and humour in the game resonated with the players well enough but not necessarily such that they would play the game when given a free choice.

\subsection{Reflection}

From the questionnaire, it is unclear to what extent players were encouraged to review and reconsider their choices through reflection. Players reported that they wanted to play again to see what would happen if they made different choices or took on different attitudes. For example, one player indicated that he wanted to compare playing as a nice guy and then as a villain, to see how that would affect outcomes.

The robot assistant was implemented to encourage transfer of reflection on in-game choices to real-world learning situations through metacognitive questions. However, the more humorous answering options of the assistant were chosen more often as it caused curiosity of the players towards the response the assistant would give. As such, the assistant was mainly regarded as comic relief, and not as much as a mentor or trainer. In this case, the narrative demoted the effectiveness of the game as players did not take the metacognitive questions posed by the assistant seriously.

\subsection{Evaluation of Features and Design Principles}

In summary, players did reflect to some extent on their choices within the game and speculated on alternative outcomes in relation to their choices. However, we found no indications for this in-game reflection to transfer to real-world learning situations. The evaluation results for each major feature is summarised in Table 2.

Table 2: An overview of evaluation results for each feature of MeCo.

\begin{tabular}{|l|l|}
\hline Game Feature in MeCo & Evaluation \\
\hline $\begin{array}{l}\text { metaphor for learning is embedded in goals } \\
\text { and narrative }\end{array}$ & $\begin{array}{l}\text { While the goals and narrative did seem to engage and motivate } \\
\text { players, the metaphor for real-world learning was not found to } \\
\text { help learners make this connection. }\end{array}$ \\
\hline $\begin{array}{l}\text { dynamically branching narrative allows } \\
\text { many different playthroughs }\end{array}$ & $\begin{array}{l}\text { While the open-ended outcomes of a dynamic narrative helped } \\
\text { to promote motivation and reflection to some extent, it also } \\
\text { increased confusion. }\end{array}$ \\
\hline $\begin{array}{l}\text { binary choice-making allows frequent } \\
\text { assessment and adjustment }\end{array}$ & $\begin{array}{l}\text { The choice-making was found meaningful during the planning } \\
\text { and performance phases but perceived as lacking } \\
\text { consequences during the evaluation phase. }\end{array}$ \\
\hline $\begin{array}{l}\text { planning, performing, and evaluating } \\
\text { adopted as the core gameplay loop }\end{array}$ & $\begin{array}{l}\text { The loop worked well as a core gameplay loop but was not } \\
\text { found to help learners see the parallel to real-world learning. }\end{array}$ \\
\hline
\end{tabular}




\begin{tabular}{|l|l|}
\hline $\begin{array}{l}\text { players control which learning goal to } \\
\text { pursue and in what way }\end{array}$ & $\begin{array}{l}\text { Players reported no difficulties in selecting and pursuing in- } \\
\text { game learning goals. }\end{array}$ \\
\hline $\begin{array}{l}\text { virtual characters simulate discussing } \\
\text { learning with peers }\end{array}$ & $\begin{array}{l}\text { Players reported no difficulties in interacting with the virtual } \\
\text { characters, but also did not see the link to real-world learning. }\end{array}$ \\
\hline direct feedback on mission success & $\begin{array}{l}\text { The direct feedback was perceived as not strong enough when } \\
\text { a mission was unsuccessful. }\end{array}$ \\
\hline $\begin{array}{l}\text { metacognitive feedback on accuracy of } \\
\text { estimating mission success }\end{array}$ & The impact of metacognitive feedback was not evaluated. \\
\hline $\begin{array}{l}\text { players explicate how a learning mission } \\
\text { was performed }\end{array}$ & $\begin{array}{l}\text { Players reported no difficulties with explicating why and how } \\
\text { the mission was performed. }\end{array}$ \\
\hline $\begin{array}{l}\text { players explicate why a learning mission was } \\
\text { successful }\end{array}$ & $\begin{array}{l}\text { Players reported no difficulties with explicating why and how } \\
\text { the mission was performed. }\end{array}$ \\
\hline $\begin{array}{l}\text { metacognitive questions connect in-game } \\
\text { fantasy to real-world learning }\end{array}$ & $\begin{array}{l}\text { The metacognitive questions were perceived as comic relief } \\
\text { more so than helpful in improving in-game or real-world } \\
\text { learning. }\end{array}$ \\
\hline
\end{tabular}

\section{Discussion}

The preliminary evaluation with a small group of students provides some indications that players were engaged in play and motivated to play the game again. While we did not evaluate for effect on metacognitive awareness, the preliminary evaluation did not find any indications of enhancing learning or reflection. In the following sections we discuss improvements to motivation and gameplay as well as to metacognitive awareness. We conclude by presenting the implications for designing GBL to enhance metacognition and future design and research steps.

\subsection{Improving Motivation and Gameplay}

Some indications for players engaging with the gameplay were found: players initially perceived their choices as meaningful and reported a willingness to re-explore them in future playthroughs. The dynamically branching storyline further contributed to making the story motivating, the choices meaningful, and, to some extent, promoting reflection on in-game choices. However, a lack of perceived consequences of previous choices on mission outcomes and confusion caused by the storyline branching unsuitably both had a detrimental effect on player engagement.

The features implemented in MeCo could be improved upon from a perspective of motivation. The dynamically branching storyline can be improved by making it more linear to prevent disengagement, however, too much linearity would defeat its purpose of enhancing reflective thought. The story and characters need to be more gradually introduced to make the players connect to them and promote conscious and meaningful choice-making. Choice-making, then, needs to have clear consequences for the success or failure of mission, such that players have something to strive for in play and re-play.

\subsection{Improving Metacognitive Awareness}

On the positive side, the different features were combined convincingly into one game design that presents a coherent set of goals, mechanics, and narrative progression. Learning and metacognition were subtly and naturally woven into the goals and narrative of the game and the SRL-cycle worked well as a core gameplay loop. However, in terms of achieving its goals of enhancing metacognitive awareness, the game is not successful at all.

The features added to the game to encourage metacognitive processes in players while playing MeCo contributed more to motivational than to metacognitive outcomes. For example, the theme and narrative referred to learning in a metaphorical way, and the core gameplay loop simulated planning, performing, and evaluating learning, but neither helped players to link gameplay experiences to real-world learning.

The features added to the game to encourage the transfer of in-game metacognitive processing to real-world learning did not help players to make this link. The metacognitive questions were perceived as comic relief more so than as helpful in improving in-game or real-world learning. In other words, the design principle of 
balancing fun and seriousness was not effectively implemented: players may have had some "fun" but did not experience any "seriousness" at all.

\subsection{Design Implications}

The current game does not succeed in connecting in-game experiences to real-world learning. The general design implication that can be taken from this design and evaluation is that the current approach is far too implicit about learning, metacognition, and the relation between in-game events and real-world learning. Enhancing metacognition through game-based learning must more explicitly address these goals through the game features and in-game interventions.

For MeCo, this implies that the theme and narrative should be more concretely focused on a learner's attempts to learn effectively and efficiently. This is corroborated by the participants' feedback that more overt references to learning would increase motivation to play and re-play, as the benefits of playing MeCo would become more apparent to them. Likewise, the metacognitive questions posed by the robot assistant should take on a more serious tone and explicitly refer to real-world learning.

For the selected design principles, this implies that some of the design principles should be emphasised. The previous discussion emphasises the importance of design principle (f): keep a balance between "fun" and "seriousness" and further elaborates this principle by advocating more explicitly addressing learning. This, in turn, emphasises design principles (a): informing learners of the goals and benefits of metacognitive training, (c): providing learners with concrete comprehension standards, and (e) implementing support aids.

\subsection{Conclusions and Future Work}

The preliminary evaluation discussed in this paper has focused on usability, user experience, motivation, and reflection. The game has yet to be evaluated for its impact on metacognitive awareness. However, additional iterations of the design and underlying design principles are needed before such an evaluation is warranted. We think that our approach of linking the underlying design principles to a concrete instantiation as an artefact supports the evaluation and advancement of such design principles through iterative design-based research.

Of particular interest in future work is whether in-game metacognitive processes can transfer to real-world learning at all. A more explicit approach to enhancing metacognition may improve its effectiveness, however, motivation and engagement could be adversely affected. This summarises a key challenge in addressing metacognition in game-based learning: striking the right balance between engaging players in motivating gameplay while addressing the serious learning objectives at the same time.

\section{Acknowledgements}

We would like to show our gratitude to Vincent Versnel, Carla van Dijk, and Kim Daanje, who created the game and conducted the evaluation as part of their studies at Hanze University of Applied Sciences, Groningen.

\section{References}

Bannert, M., \& Mengelkamp, C. (2013). Scaffolding hypermedia learning through metacognitive prompts. In International handbook of metacognition and learning technologies (pp. 171-186). Springer, New York, NY.

Brown, A. L. (1978). Knowing when, where, and how to remember: A problem of metacognition. Advances in Instructional Psychology. Volume 1, 225-253.

Castronovo, F., Van Meter, P. N., \& Messner, J. I. (2018). Leveraging metacognitive prompts in construction educational games for higher educational gains. International Journal of Construction Management, 1-12.

Charles, D., Hanna, C., Paul, R., \& Charles, T. (2012, October). Rapid development of games inspired metacognitive learning experiences using moodle and gamemaker. In Proceedings of the 6th European Conference on Games Based Learning, 93-101.

Derry, S. J., \& Murphy, D. A. (1986). Designing systems that train learning ability: From theory to practice. Review of educational research, 56(1), 1-39.

Flavell, J. H. (1976). Metacognitive aspects of problem solving. The nature of intelligence, 231-235.

Jacobs, J. E., \& Paris, S. G. (1987). Children's metacognition about reading: Issues in definition, measurement, and instruction. Educational psychologist, 22(3-4), 255-278. 
Ke, F. (2016). Designing and integrating purposeful learning in game play: A systematic review. Educational Technology Research and Development, 64(2), 219-244.

Kim, B., Park, H., \& Baek, Y. (2009). Not just fun, but serious strategies: Using meta-cognitive strategies in game-based learning. Computers \& Education, 52(4), 800-810.

Koenig, J. A. (2011). Assessing 21st century skills: Summary of a workshop. Social Sciences, 2-5.

Lin, X. (2001). Designing metacognitive activities. Educational Technology Research and Development, 49(2), 23-40.

Mayer, R. E. (2016). The Role of Metacognition in STEM Games and Simulations. In H. F. O’Neil, E. L. Baker, \& R. S. Perez (Eds.), Using Games and Simulations for Teaching and Assessment: Key Issues. New York: Routledge.

Nerial. (2016). Reigns. Devolver Digital.

Nietfeld, J., \& Shores, L. R. (2011). Self-Regulation Within Game-Based Learning Environments. In Serious Educational Game Assessment (pp. 19-42).

Osman, M. E., \& Hannafin, M. J. (1992). Metacognition research and theory: Analysis and implications for instructional design. Educational Technology Research and Development, 40(2), 83-99.

Plass, J. L., Homer, B. D., \& Kinzer, C. K. (2015). Foundations of Game-Based Learning. Educational Psychologist, 50(4), 258-283.

Schraw, G. (1998). Promoting general metacognitive awareness. Instructional Science, 26(1), 113-125.

Sitzmann, T. (2011). A meta-analytic examination of the instructional effectiveness of computer-based simulation games. Personnel Psychology, 64(2), 489-528.

Veenman, M. V. J. J., Van Hout-Wolters, B. H. A. M., \& Afflerbach, P. (2006). Metacognition and learning: conceptual and methodological considerations. Metacognition and Learning, 1(1), 3-14.

Verpoorten, D., Castaigne, J.-L., Westera, W., \& Specht, M. (2012). A quest for meta-learning gains in a physics serious game. Education and Information Technologies, 19(2), 361-374.

Zimmerman, B. J., \& Campillo, M. (2003). Motivating self-regulated problem solvers. The psychology of problem solving. 